\title{
Guest Comment: Leukaemia \& Lymphoma Awareness Month
}

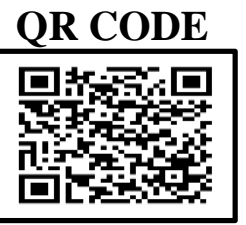

\section{DR. PREETY GUPTA}

Every year, the month of September is celebrated as Leukaemia \& Lymphoma Awareness Month. This is done to increase the general public's understanding regarding cancers of hematologic origin and their early warning symptoms. The main aim of making this effort is to enhance the people's knowledge about the prevalence of these life-threatening conditions, and also to point people to trusted information resources, so that the likelihood of early detection is increased and better outcome is achieved. Many of the affected people are able to successfully get treated and overcome these conditions and are also able to maintain a high quality of life, all due to recent research advances.

The cancers that affect the blood or bone marrow are scientifically known as leukaemias and lymphomas.

Leukaemia is a kind of cancer that initiates in the blood forming tissues and most of the blood cells develop from stem cells found in the bone marrow. Leukaemia cells are abnormal white blood cells that are formed in a person suffering from leukaemia. These leukaemia cells don't die when they should, unlike normal blood cells. They make it hard for normal blood cells to do their work.

According to federal statistics, in 2019, adult leukaemias are expected to account for around 3.5 percent of all new cancer cases, with leukaemia being the most common cancer in children less than 15 years of age.

Leukaemia's are classified into four major types: AML, acute myeloid leukaemia, that affects myeloid cells and has a quick growth; CLL, chronic lymphocytic leukaemia, affecting lymphoid cells and has a slow growth; ALL, acute lymphocytic leukaemia affecting lymphoid cells and has a quick growth; and lastly CML, chronic myeloid leukaemia which has an effect on myeloid cells and usually has a slow growth initially. Adults are mainly affected by AML and CLL while ALL is the most common leukaemia affecting the children.

Despite successful treatment, childhood leukaemia stands as the principal subtype of paediatric cancer with enigmatic etiology. Researchers have proposed a plethora of candidate environmental exposures, but almost all of them lack a biological rationale or consistent epidemiological evidence. ${ }^{1}$

Lymphatic system is a part of the human immune system where the lymphomas originate. Lymphoma can initiate anywhere in the human body due to throughout presence of the lymphatic tissue. These can be basically classified into two categories, Hodgkin and non-Hodgkin lymphomas.

The presence of a Reed-Sternberg cell in the lymph nodes is the marking characteristic of Hodgkin lymphoma and this lymphoma may occur commonly in patients affected by acquired immunodeficiency syndrome.

Categorized by scientists typically as either slowgrowing or aggressive, Non-Hodgkin lymphomas include a vast, diversified group of cancers of immune system cells, with diffuse large B-cell lymphoma and follicular lymphoma being the most common types of NHL in adults. According to the National Cancer Institute, these lymphoma represents approximately 4.2 percent of all new cancer cases in the United States of America. Both kind of lymphomas can occur in children and adults.

Timely and accurate estimation and detection followed by precise assessment of therapeutic treatment response is of prime importance for the optimal management of subjects affected with lymphoma. Over the last 5 decades, drastic advances in technological development has led to establishment of imaging as the cornerstone for evaluation of disease. But the appropriate application of current techniques requires thorough knowledge of their strengths and weaknesses, along with the 
appreciation of the huge diversity of neoplasms of lymphoid tissue. ${ }^{2}$

In the year 1949, a society was established as the de Villiers Foundation. In the year 2000, its name was changed from The Leukaemia Society of America to The Leukaemia \& Lymphoma Society (LLS). This initiative was taken to emphasize the commitment of society against fighting all blood-borne cancers. The inaugural edition of the Report to the Nation on Blood Cancer: Leading the Way to Cancer Cures in 2017 was released to provide education and get people engaged in the battle against blood cancers namely, lymphomas, leukaemia's and myelomas which stand at third position in the list of leading causes of cancer related deaths in United States of American. In the same year, the U.S. Food and Drug Administration approved unrivalled treatment options (eighteen in number) for subjects who were in urgent need. For all of these advancements, the Leukaemia \& Lymphoma Society has played a vital role and in recent decades, the research supported by this body has significantly contributed to almost every new blood cancer treatment strategy and innovative approach including immunotherapy and precision medicine. ${ }^{3}$

\section{REFERENCES}

1.Greaves M. Infection, immune responses and the aetiology of childhood leukaemia. Nat Rev Cancer 2006;6:193.

2. Cunningham J, Iyengar S, Sharma B. Evolution of lymphoma staging and response evaluation: current limitations and future directions. Nature Reviews Clinical Oncology 2017;14:631-45.

3. https://www.lls.org [Last accessed on $15^{\text {th }}$ July, 2019]
Cite this article as:

Gupta P. Guest Comment: Leukaemia \& Lymphoma Awareness Month. In Healthc Res J. 2019;3(6):189-190. https://doi.org/10.26440/IHRJ/0306.09281

\section{Author Details \& Corresponding Address:}

MDS (Public Health Dentistry) (ORCID ID: https://orcid.org/oooo-0oo2-5382-3372)

Reader

Department of Public Health Dentistry

Swami Devi Dyal Hospital and Dental College

Barwala, Panchkula

Haryana, India

dr.preety86[at]gmail[dot]com 